\title{
FORMAS DE TRABALHO "NÃO CAPITALISTAS” NO CAPITALISMO: SOBREVIVÊNCIA HISTÓRICA OU PARTE INTEGRANTE?
}

\author{
RODNEY DA SILVA AMADOR ${ }^{1}$
}

\begin{abstract}
Resumo: O presente artigo tem como objetivo fazer uma pequena contribuição para uma discussão já clássica entre os autores - ditos ou reconhecidos - marxistas, afinal, as chamadas formas não capitalistas de trabalho, isto é, que não são remuneradas na forma de um salário (servidão, escravidão, trabalho voluntário) consiste numa sobrevivência de outros meios de produção ou são parte integrantes do capitalismo? Desta forma, situamos argumentos tanto de um lado da questão quanto de outro, mostrando diferentes vertentes às quais autores marxistas se vinculam. O texto está dividido em três partes: uma breve introdução, uma análise da questão da acumulação primitiva em Marx e, por fim, uma análise de autores que pensaram a questão das formas de traba lho e seus dilemas. Nesta terceira parte, também se levanta certos problemas mais atuais e propostas que levem em consideração debates políticos como a reforma da previdência e a reforma trabalhista.
\end{abstract}

Palavras-chave: Capitalismo, Modos de produção, Formas de trabalho

\section{INTRODUÇÃO}

O objetivo deste ensaio é analisar a existência — ou a continuidade — de formas “não capitalistas” de trabalho dentro do modo de produção capitalista. O tema é bastante im portante para a compreensão do mundo a partir dos pressupostos do materialismo histórico dialético: se o capitalismo tende a tornar tudo mercadoria, inclusive a força de trabalho, levando o trabalhador a vendê-la em troca de um salário, como propôs Marx no Capital, o que explica que grande parte dos trabalhadores no mundo - na verdade, a maior parte da força de trabalho mundial encontra-se nessa situação - não ser composta por trabalhadores assalaria-

$1 \quad$ Aluno do Curso de Ciências Sociais da Faculdade de Filosofia, Letras e Ciências Humanas da USP (FFLCH). Assistente de pesquisa no CEBRAP e bolsista de iniciação científica da FAPESP.

rodney.amador@usp.br 
Formas de trabalho "não capitalistas" no capitalismo: sobrevivência histórica ou parte integrante?

dos? As soluções para esse dilema, conforme será brevemente apresentada aqui variam entre supor que essas outras formas de trabalho existem como uma sobrevivência histórica, algo que não deveria mais estar lá e, no entanto, está, ou como um aspecto integrante, estrutural, da moderna economia mundial.

Antes desse debate, no entanto, faz-se necessário algumas definiçốes para indicar o quadro teórico no qual este ensaio se encontra: o que são formas "capitalistas" e "não capitalistas” de trabalho? Além disso, faz-se também necessário abordar questóes como "acumulação primitiva de capital” e “apropriação por espoliação”, afinal, se o capitalismo é um fenômeno histórico, ele teve uma origem no espaço e no tempo e se ele se expande para áreas geográficas "não capitalistas", como isso pode ser feito? Somente a partir disso, esta discussão sobre formas de trabalho pode ser colocada e compreendida.

1 ACUMULAÇÃO PRIMITIVA DE CAPITAL?

Considera-se como forma não capitalista de trabalho todas as formas que não resultam de uma venda da força de trabalho, isto é, a partir de um salário. O que caracteriza o trabalho no capitalismo é a sua relação com a produção de mercadorias. No entanto, no livro O Capital (MARX, 2014, p. 312-313), Marx expõe a forma como a força de trabalho, ela própria, se constitui em mercadoria, e é a única cujo consumo gera mais-valor a quem a compra ao ser "utilizada". Ao longo do Capítulo 4, Marx explica a forma como o trabalho é vendido e comprado dentro do sistema e em dado momento, afirma:

\footnotetext{
Uma coisa, no entanto, é clara: a natureza não produz possuidores de dinheiro e de mercadorias, de um lado, e simples possuidores de suas próprias forças de trabalho, de outro. Essa não é uma relação histórico-natural [naturgeschichtliches], tampouco uma relação social comum a todos os períodos históricos, mas é claramente o resultado de um desenvolvimento histórico anterior, o produto de muitas revoluções econômicas, da destruição de toda uma série de formas anteriores de produção social. (MARX, 2014, p. 314-315).
}

Marx, neste trecho, indica algo bastante importante: a relação de trabalho que está descrevendo é uma invenção recente. Ao longo da história, a forma assalariada ou remunerada de mão de obra nunca ocupou um lugar central, ainda que existisse. $\mathrm{Na}$ antiguidade clássica, havia a escravidão no centro do modo de produção; no feudalismo, a servidão ${ }^{2}$. So2 Cf. REZENDE, 1991, Cap. 1, 2 e 3. 
mente no capitalismo, a mão de obra assalariada, com a apropriação feita sobre os resultados do trabalho - e não mais sobre o trabalhador, enquanto escravo/propriedade e nem sobre o próprio trabalho, enquanto servo - tornou-se central. Marx conclui dizendo que resta ao trabalhador vender, ele próprio, sua pele no mercado (2014, p. 323).

No entanto, se esta forma de trabalho não é obra da natureza, o que explica sua origem? Novamente, Marx analisa esse problema no capítulo 24 do mesmo livro, intitulada "A assim chamada acumulação primitiva 3" (2014, p. 959). Se alguém tem capital para comprar força de trabalho, bem como os meios necessários para produzir mercadorias - fábricas, máquinas, terras etc. - algo aconteceu que lhe permitiu isso. Em outras palavras, o que fez com que uns tivessem os meios de produção e outros tivessem apenas a sua força de trabalho? A isso, Marx chamou de acumulação primitiva.

Deu-se, assim, que os primeiros acumularam riquezas e os últimos acabaram sem
ter nada para vender, a não ser sua própria pele. E desse pecado original datam a
pobreza da grande massa, que ainda hoje, apesar de todo seu trabalho, continua a
não possuir nada para vender a não ser a si mesma, e a riqueza dos poucos, que
cresce continuamente, embora há muito tenham deixado de trabalhar [...] Na his-
tória real, como se sabe, o papel principal é desempenhado pela conquista, a subju-
gação, o assassínio para roubar, em suma, a violência. Já na economia política, tão
branda, imperou sempre o idílio. Direito e "trabalho" foram, desde tempos ime-
moriais, os únicos meios de enriquecimento, excetuando-se sempre, é claro, "este
ano". Na realidade, os métodos da acumulação primitiva podem ser qualquer coi-
sa, menos idílicos. (MARX, 2014, p. 960).

O autor então descreve, em conflito com os autores liberais da economia política inglesa, que na verdade, o trabalho assalariado enquanto centro da economia, a divisão social entre possuidores e despossuídos e, desta forma, o modo de produção capitalista em si, resul tou de um processo de expropriação dos meios de produção da mão dos produtores, convertidos em trabalhadores, proletariados. O exemplo padrão disto, exposto também por Marx, é o processo de cercamentos das terras comunais na Inglaterra que, por força da lei e do exército, expulsou os camponeses de suas terras - agora utilizadas para a criação de ovelhas e a produ -

3 O nome original do capítulo é "Die sogenannte ursprüngliche Akkumulation”, no qual a palavra ursprüngliche significa "originária” e não propriamente "primitiva” como se utiliza neste texto, a partir da tradução de 2014 do Capital de Marx. No entanto, acredito que não há perda de sentido, pelo menos da forma como se está sendo trabalhada neste breve estudo, já que ambas as palavras dão a entender que a acumulação descrita por Marx está mais associada ao começo do capitalismo do que a sua continuidade. Ambas expressam um ponto anterior no tempo. Agradeço ao parecerista anônimo pelo comentário a respeito disso. 
Formas de trabalho "não capitalistas" no capitalismo: sobrevivência histórica ou parte integrante?

ção de lã. Os camponeses, sem nenhuma outra possibilidade de sobrevivência, foram arranjar emprego nas cidades, aí já como assalariados. Isso tornou possível a acumulação do tipo capitalista - mais-valor sobre o trabalho - antes mesmo da revolução industrial.

É importante destacar que a origem histórica do sistema capitalista tenha sido colocada ao final do livro 1 do Capital. Como afirma Perelman (2000, p. 29-30), a preocupação de Marx não está em denunciar, ou mesmo explicar, a acumulação primitiva, e sim a exploração já dentro do sistema capitalista constituído. Queria mostrar que a violência não estava restrita a esse "pecado original" do capitalismo, mas sim a todo o seu desenvolvimento.

\begin{abstract}
Marx would not have wished his readers to believe that measures to eliminate "unjust" instances of primitive accumulation might suffice to bring about a good society. To have stressed the continuing influence of primitive accumulation would have risked throwing readers off track. Certainly, Marx did not want his readers to conclude that the ills of society resulted from unjust actions that were unrelated to the essence of a market society. On the contrary, Marx insisted that the law of supply and demand, not primitive accumulation, was responsible for the better part of the horrible conditions that the working class experienced. (PERELMAN, 2000, p. 30). ${ }^{4}$
\end{abstract}

O problema, porém, está em algo que o próprio Perelman reconhece (2000, p. 29): Marx não é conclusivo sobre quando o processo de acumulação primitiva termina. $\mathrm{Na}$ verdade, o próprio uso do termo "primitivo" indica que, para Marx, tratava-se de um fenômeno relegado ao passado. Uma vez feita, os capitalistas teriam chegado à conclusão de que é mais fácil e seguro um tipo de acumulação que não precisasse recorrer à violência e à expropriação direta. A história, por outro lado, indica que o processo descrito por Marx não pode ser restrito ao passado: a expropriação continua, conforme o capitalismo expande a sua área geográfica. Em outras palavras:

Specifically, by relegating primitive accumulation to the precapitalistic past, we lose sight of the twofold time dimension of primitive accumulation. First, as we

\footnotetext{
4 “Marx não desejaria que seus leitores acreditassem que medidas para eliminar instâncias 'injustas' de acumulação primitiva poderiam ser suficientes para criar uma boa sociedade. Ter enfatizado que a contínua influência da acumulação primitiva teria arriscado jogar fora os leitores. Certamente, Marx não queria que seus leitores concluíssem que os males da sociedade resultaram de açôes injustas que não estavam relacionadas à essência de uma sociedade de mercado. Ao contrário, Marx insistiu que a lei da oferta e da demanda, não a acumulação primitiva, era responsável pela melhor parte das condiçôes horríveis que a classe trabalhadora vivenciava" (Tradução livre).
} 
shall emphasize later, the separation of people from their traditional means of production occurred over time as capital gradually required additional workers to join the labor force. Second, the process of primitive accumulation was a matter of degree. (PERELMAN, 2000, p. 32). ${ }^{5}$

Ao longo do século XX, principalmente a partir de sua segunda metade, este debate ganhou corpo devido ao surgimento de novas abordagens que tentavam ir além da - ou mesmo em conflito com a - abordagem marxiana. Deixando de lado a abordagem liberal ou smithiana, este ensaio quer focar principalmente em duas tendências que apresentam entendimentos diferentes sobre acumulação primitiva: o marxismo ortodoxo e a análise de sistemamundo - world-systems analysis (MIELANTS, 2012). Essas abordagens também propóem compreensões diferentes sobre as formas de trabalho não capitalistas dentro do capitalismo: seria uma continuidade ou algo integrante?

Para exemplificar as posições acima citadas, foram selecionados autores identificados com as mesmas. Alguns desses textos são mais antigos e alguns de seus pontos já foram devidamente criticados em textos mais recentes. No entanto, acredita-se que ainda podem ser citados como paradigmas destas posições, principalmente por terem em seu escopo de análise a realidade brasileira. A América Latina, em muitos aspectos, é um lugar muito próprio para o estudo dessa questão, devido a sua amplitude geográfica, desenvolvimento histórico e uma das desigualdades sociais mais drásticas do mundo. Quase todas as formas de trabalho até então estudadas, da subsistência à prestação de serviço, passando por servidão, escravidão e assalariamento, existiram aqui nos últimos cinco séculos — já num período considerado capitalista por diversos autores ${ }^{6}$. Mielants descreve com detalhes essas posições, que pode servir de ponto inicial para a diferenciação proposta aqui:

5 "Especificamente, relegando a acumulação primitiva ao passado pré-capitalista, perdemos de vista a du pla dimensão temporal da acumulação primitiva. Primeiro, como enfatizaremos mais adiante, a separação das pessoas de seus meios tradicionais de produção ocorreu ao longo do tempo, à medida que o capital gradualmente exigiu a entrada de mais trabalhadores para se juntar à força de trabalho. Em segundo lugar, o processo de acumulação primitiva era uma questão de grau” (Tradução livre).

$6 \quad$ PRADO Jr., 2011 e REZENDE, 1991, por exemplo. 
Formas de trabalho "não capitalistas" no capitalismo: sobrevivência histórica ou parte integrante?

Wallerstein, considered by many as the founding father of world-system analysis, essentially defined the capitalist world-economy, or modern world-system, as a socioeconomic entity that emerged in sixteenth-century Europe and subsequently expanded to incorporate more areas of the world such as the surrounding minisystems and world-empires, which operated according to a different logic. Characterized by a global division of labor resulting from intense yet unequal bulk trade linkages and illustrated by commodity chains between different zones that he labeled core, periphery, and semiperiphery, this capitalist world-system gradually expanded from $1492 \mathrm{CE}$ until the end of the nineteenth century when the entire world had become capitalist. As stated earlier, this theoretical position ran counter to the Orthodox Marxism embraced by the Soviet Union and Communist Parties as well as intelligentsia allied to them. [...]. Many of his statements were essentially "contextual observations dependent on his analysis of the capitalist production" during the industrial era. The focus of Marx and Engels on Britain (and their subsequent characterization of non-European areas of the world as Oriental Despotism) was continued in the twentieth century by renowned Marxist scholars such as Maurice Dobb and Robert Brenner, who also juxtaposed the general socioeconomic feudal crisis "on most of the continent" with the "critical breakthrough to self-sustaining growth in England." More recently, Georges Comninel and Ellen Meiskins Wood have updated this Orthodox Marxist perspective. For the latter, the seventeenth-century world-economy was mainly trade in luxury goods being bought cheaply and sold dearly to make profit-so-called merchant capitalism, not real industrial capitalism using wage labor. England was a unique place with unique agricultural conditions, its "internal market" and its "capitalism in one country." This exceptional island was capable of becoming on its own the first capitalist nation-state. (MIELANTS, 2012, pp. 56-57). ${ }^{7}$

7 "Wallerstein, considerado por muitos como o pai fundador da análise do sistema mundial, definiu essencialmente a economia-mundo capitalista, ou sistema-mundo moderno, como uma entidade socioeconômica que emergiu na Europa do século XVI e, subsequentemente, se expandiu para incorporar mais áreas do mundo, como os mini-sistemas e impérios mundiais que operavam de acordo com uma lógica diferente. Caracterizado por uma divisão global do trabalho resultante de vínculos comerciais intensos, porém desiguais, e ilustrado por cadeias de mercadorias entre diferentes zonas que ele denominou núcleo, periferia e semiperiferia, esse sistemamundo capitalista expandiu-se gradualmente de 1492 a.C. até o final do século XIX quando o mundo inteiro se tornou capitalista. Como dito anteriormente, essa posição teórica contraria o marxismo ortodoxo adotado pela União Soviética e pelos partidos comunistas, assim como a intelligentsia aliada a eles [...]. Muitas de suas declaraçốes eram essencialmente "observaçôes contextuais dependentes de sua análise da produção capitalista" durante a era industrial. O foco de Marx e Engels na Grã-Bretanha (e sua subsequente caracterização de áreas não euro peias do mundo como o Despotismo Oriental) foi continuado no século XX por renomados estudiosos marxistas como Maurice Dobb e Robert Brenner, que também justapunham a crise geral e socioeconômica feudal "na maior parte do continente" com o "avanço crítico para o crescimento auto-sustentável na Inglaterra". Mais recentemente, Georges Comninel e Ellen Meiksins Wood atualizaram essa perspectiva marxista ortodoxa. Para o último, a economia mundial do século XVII era principalmente o comércio de bens de luxo sendo comprados a preços baixos e vendidos com muito carinho para obter lucro - o chamado capitalismo mercantil, e não o capitalis mo industrial real que usa mão-de-obra assalariada. A Inglaterra era um lugar único, com condições agrícolas 
O trecho é particularmente importante para mostrar qual seria a diferença fundamental entre essas duas análises. Para uma, a economia mundial está estabelecida em um sistema, isto é, por definição, algo no qual as diferentes partes estabelecem uma relação entre si, cuja mudança de uma dessas partes afetam as outras e o sistema como um todo. Devido a troca desigual entre as regióes do mundo, umas com mais poder e tecnologia, produzindo produtos com alto valor agregado e outras, mais pobre e pouco desenvolvidas, produzindo produtos com baixo valor agregado, resultando numa divisão centro/periferia. Isso sem falar em relações de monopólio e monopsônio estabelecidas entre as Américas e a Europa até o início do século XIX, conforme indica Braudel um uma conferência publicada em 1987 (BRAUDEL, 1987, pp. 43-47). Para este autor, ademais, o capitalismo deveria ser considerado como a própria inversão de uma economia de mercado, o contra-mercado. A outra perspectiva fala de um modo de produção capitalista que, de certa forma começa praticamente "em um só país" no caso a Inglaterra - e que se alastra conforme a necessidade para outros países e regióes do mundo. Ao chegar nestes lugares, progressivamente, vai substituindo as relaçóes lá existentes - muitas vezes classificadas com termos específicos como "feudais" ou com adjetivos mais vagos como "pré-capitalistas” - por relações capitalistas.

O texto do historiador Sérgio Silva (1986) ilustra a segunda perspectiva. Ao analisar a passagem da economia cafeeira para a industrial no Brasil do final do século XIX e início do século XX, Silva utiliza a ideia de "fase de transição":

\footnotetext{
O desenvolvimento das forças produtivas sob a dominação do capital não é somente desenvolvimento das forças produtivas; é também desenvolvimento das relaçóes sociais capitalistas. Em outras palavras, o reforço da dominação do capital sobre o trabalho. Os dois processos estão intimamente ligados, de modo que um não existe sem o outro. Não há desenvolvimento das forças produtivas, senão sob relações de produção dadas. Todo desenvolvimento de relações de produção implica um tipo específico de desenvolvimento das forças produtivas e, portanto, a transformação das relaçóes técnicas de produção correspondentes às antigas relações de produção (SILVA, 1986, p. 14).
}

Justiça seja feita, o autor reconhece que as relações capitalistas subordinam as outras formas de trabalho, de modo que a existência dessas últimas não compóe uma sobrevivên-

únicas, seu "mercado interno" e seu 'capitalismo em um país'. Essa ilha excepcional era capaz de se tornar por si só o primeiro estado-nação capitalista" (Tradutor livre). 
cia (idem, p. 16), mas são parte integrante do sistema capitalista, como será abordado mais à frente, a partir da outra perspectiva. No entanto, como afirmado, o autor entende que o capitalismo brasileiro como em transiz̧ão, a partir de um capitalismo que vem de fora, expandindo-se pelo mundo. Mais à frente (idem, a partir da página 24), o autor aborda a ideia de exportação de capital: os países que já passaram para a fases superiores do capitalismo exportam seu excedente de capital para os países ainda em transição, já que este tipo de exportação se tornou mais rentável e importante do que a própria exportação de produtos. Exemplo disso é a malha ferroviária brasileira, principalmente a existente no eixo Rio de Janeiro-São Paulo, toda financiada com capital inglês, sob o qual incidiam juros ainda que quase sempre negociáveis. Isso muito tem a ver com o que outro grande autor marxista, David Harvey (HARVEY, 2005 , p. 121) chamou de "acumulação via espoliação". Novamente, o problema da acumulação primitiva vem à tona: para Harvey, ela não se restringe a uma origem histórica do capitalismo, mas é parte fundamental do seu desenvolvimento. Sempre que o modo de produção atinge um determinado "teto" de possibilidades de investimento, surgem crises de sobreacumulação, isto é, excesso de capital ocioso, supérfluo. O resultado é o aumento das possibilidades de investimento, seja exportando capital, seja privatizando empresas, comprando terras, expulsando comunidade de regióes ancestrais - o caso descrito pelo autor do México da década de 1990 (2005, p. 132) é emblemático. O capitalismo assim, aumenta sua área geográfica, chegando a lugares e a relações que ainda não haviam sido incluídas.

É importante destacar, no entanto, que os autores, de certa forma, insistem que o capitalismo avança - ou, para alguns autores como Maurice Dobb, evolui - "revolucionarizando", como afirma Sérgio Silva (SILVA, 1986, p. 14) o que existe antes ou, em outras palavras, modificando profundamente o que já existe, deixando irreconhecível. Isso torna mais difícil entender a continuidade de formas de trabalho não capitalistas, o que acaba caindo numa ideia de contradição. Hoje tornou-se mais difícil algum autor definir o Brasil ou a América Latina atual como em uma fase de transição para formas mais desenvolvidas de capitalismo. Nesse sentido, a segunda perspectiva, numa análise de sistema-mundo - e mais especificamente aqui, a partir do que ficou conhecido como Teoria da Dependência - propóe outras saídas, bastante interessantes.

Num ensaio de 1972 chamado "Crítica à razão dualista”, o sociólogo Francisco de Oliveira polemizou a respeito desse tema com diversos outros autores. Os alvos por excelência de sua crítica eram os pesquisadores relacionados com a Comissão Econômica para América Latina e Caribe (Cepal). Para ele, esses autores estariam imbuídos de uma "razão dualista”, vendo o atraso brasileiro como uma excrescência. Em suas palavras: 
Assim, boa parte da intelectualidade latino-americana, nas últimas décadas, dilacerou-se nas pontas do dilema: enquanto denunciavam as miseráveis condiçóes de vida de grande parte da população latino-americana, seus esquemas teóricos e analíticos prendiam-nos às discussões em torno da relação produto capital, propensão para poupar ou investir [...]. A dualidade reconciliava o suposto rigor científico das análises com a consciência moral, levando a proposiçôes reformistas (OLIVEIRA, 2003, pp. 30-31).

Para o autor, a solução passava por entender que "o 'subdesenvolvimento' é uma formação capitalista e não simplesmente histórica” (2003, p. 33). Isto é, de certa forma, rompe-se com uma determinada ideia de transição. A forma como o Brasil entra na economia mundial é a partir do seu subdesenvolvimento, a partir de uma relação periférica com outras áreas. A partir disso - algo que é fundamental para este ensaio - o autor afirma que formas não capitalistas continuam a existir no Brasil justamente para assegurar e manter o tipo de acumulação capitalista aqui instaurado. Para Oliveira, a agricultura no Brasil é mantida de forma arcaica, com toda sorte de relação de trabalho - nem sempre fiscalizada, nem sempre regulamentada, nem sempre assalariada - para que o preço dos alimentos se mantenham em baixa, o que reduz o salário nas fábricas da cidade (2003, pp. 42-50); bem como o setor de serviços brasileiro cresce de forma "irregular", baseando-se em trabalhos informais e não regulamentados justamente devido ao drástico e corrido desenvolvimento urbano e industrial: não era possível que o setor de serviços acompanhasse a indústria sem sofrer de falta de estrutura (2003, pp. 54-60). O autor afirma:

\footnotetext{
Mesmo certos tipos de serviços estritamente pessoais, prestados diretamente ao consumidor e até dentro das famílias, podem revelar uma forma disfarçada de exploração que reforça a acumulação. Serviços que, para serem prestados fora das famílias, exigiriam uma infraestrutura de que as cidades não dispốem e, evidentemente, uma base de acumulação capitalística que não existe. A lavagem de roupa em casa somente pode ser substituída em termos de custo por lavagem industrial que compita com os baixos salários pagos às empregadas domésticas; o motorista particular que leva as crianças à escola somente pode ser substituído por um eficiente sistema de transportes coletivos que não existe. Comparado com um americano médio, um brasileiro da classe média, com rendimentos monetários equivalentes, desfruta de um padrão de vida real mais alto, incluindo-se neste todo tipo de serviços pessoais no nível da família, basicamente sustentado na exploração de mão de obra, sobretudo feminina (2003, p. 58).
} 
Formas de trabalho "não capitalistas” no capitalismo: sobrevivência histórica ou parte integrante?

O autor então indica que os níveis de acumulação no Brasil só são possíveis por que uma parte desses serviços, no primeiro e no terceiro setor, são postos fora dos custos internos de produção (2003, p. 69), isto é, não são pagos, no sentido de que ou o Estado não dispóe - e, portanto, não cobra impostos sobre os ganhos da forma como deveria - ou o ca pitalista não paga — na forma de redução do salário. Quanto mais o salário se reduz, mais dramática é essa situação: realiza-se autoconstrução de casas para moradia; deixa-se os filhos com a mãe que não sai de casa para trabalhar, ou com um parente que não cobra o serviço de babá, ao invés de deixar em uma creche; etc. Isso é bem analisado no texto de Donald Clelland (2014) a respeito da cadeia global de produção da empresa Apple. A partir da ideia de dark value, o autor mostra que muito dos custos de reprodução da mão de obra, por exemplo, não são remunerados e isso contribui para a acumulação capitalista. Para o autor, "The capitalist world-economy takes the form of an iceberg. The most studied part which appears above the surface is supported by a buge underlying structure that is out of sight" ${ }^{8}$ (2014, p. 82), isto é, a maior parte do sistema encontra-se abaixo da superfície.

Por fim, algumas coisas podem ser concluídas ou sugeridas a partir dessa análise. A primeira é que a economia de um país reproduz a divisão centro/periferia da economia mundial, no sentido de que há atividades - relacionadas à produção - que ocupam o centro da economia e que possui alto valor monetário - pagam-se salários altos - e alto valor social — são regulamentadas e respeitadas, com sindicatos e organizações próprias; e há atividades - relacionadas à reprodução - que ocupam a periferia da economia: os salários, quando existem, são baixos, há pouca regulamentação e baixo valor social. A segunda é que as duas perspectivas analisadas aqui não parecem - ou, pelo menos, não deveriam - ser colocadas como tão opostas: o capitalismo avança, transforma, expropria e acumula, porém, o resultado não é outro país capitalista como aquele do qual o modo de produção "se derivou”, o que se vê é o surgimento de uma dependência, de uma desigualdade.

Portanto, análises como, por exemplo, da nova lei trabalhista brasileira, aprovada em 2017, ou mesmo da reforma da previdência, não podem ser feitas apenas nos termos de uma reestruturação produtiva, isto é, a partir somente de fatores internos à economia brasilei ra. Deve-se levar em consideração fatores externos, como a necessidade de se manter o Brasil na posição de subalterno, em eterna disputa por investimentos estrangeiros e empresas multi-

$8 \quad$ "A economia mundial capitalista assume a forma de um iceberg. A parte mais estudada que aparece acima da superfície é suportada por uma enorme estrutura subjacente que está fora de vista” (Tradução livre). 
nacionais. Ou ainda, em outras palavras, manter-se naquilo que Andre Gunder Frank chamou de o "desenvolvimento do subdesenvolvimento". 
Formas de trabalho "não capitalistas" no capitalismo: sobrevivência histórica ou parte integrante?

REFERÊNCIAS BIBLIOGRÁFICAS

BRAUDEL, F. A dinâmica do capitalismo. Rio de Janeiro: Rocco. 1987.

CLELLAND, D. The Core of the Apple: Dark Value and Degrees of Monopoly in Global Commodity Chains. Journal of World-Systems Research. v. 20, n. 1, pp. 64-81, 2014.

HARVEY, D. Acumulação por espoliação. In: O Novo imperialismo. Rio de Janeiro: Loyola, 2005 .

MARX, K. O capital: crítica da economia política. São Paulo: Boitempo, 2014.

MIELANTS, E. The great transition debate and world-systems analysis. In: BABONES, S. J \& CHASE-DUNN, C. K. Routledge Handbook of World-Systems Analysis. Londres e Nova York, Routledge, 2012, p. 56-62.

OLIVEIRA, F. Crítica à razão dualista. In: OLIVEIRA, F. Critica à razão dualista e O ornintorrinco. São Paulo: Boitempo, 2003.

REZENDE, C. de B. História econômica geral. São Paulo: Contexto, 1991.

PERELMAN, M. The Invention of Capitalism: Classical Political Economy and the Secret History of Primitive Accumulation. Duke University Press, 2000.

PRADO Jr., C. Formação do Brasil contemporâneo: colônia. São Paulo: Companhia das Letras, 2011.

SILVA, S. Expansão cafeeira e origens da indústria no Brasil. São Paulo: Alfa-Ômega, 1986. 